\title{
EVOLUTION OF THE COMPONENTS OF SPORTSMANSHIP AND AGGRESSION IN TERMS OF WATER POLO PLAYER POSITIONS
}

\author{
Barbara Dávid1, Csilla Csukonyi 1, Dorottya Ocsenás1, Sándor Kardos ${ }^{2}$ \\ 1 University of Debrecen, Faculty of Arts, Institute of Psychology, Debrecen, Hungary \\ ${ }^{2}$ Civis Póló SE, Debrecen, Hungary
}

\begin{abstract}
Two commonly used constructs in sport psychology researches are aggression and sportsmanship. In the present research, we attempted to assess the correlations between these two phenomena among male water polo players. The main objective was to explore the differences in aggression in the sport-specific positions of water polo in different aspects - physique, age, etc. - considered. Furthermore, the research sought to demonstrate the inverse relationship between aggression and sportsmanship in a water polo sample. To access these constructs in our research besides the BussPerry Aggression Questionnaire and the Sportsmanship Attitude Scale a self-formulated water polo specific questionnaire was used, which intended to measure the aggression in the water during water polo matches. From the results, it can be seen that, according to our sample, both the trait aggression of the players and the role determined by their positions in the game play a decisive role when it comes to the aggression of an athlete. Moreover, the results obtained for water polo players also proved that sportsmanship and aggression are two contradictory constructs.
\end{abstract}

Keywords: sport psychology, water polo, aggression, sportsmanship

\section{THEORETICAL BACKGROUND}

It can be observed that there are phenomena that are treated differently in the context of sport than in other areas of life. Aggression is not only an accepted but celebrated, encouraged form of behavior in some sports that is not tolerated in this way when it appears in other situations. In addition, sportsmanship, to behave in a "fair" way, takes on an important role in sport, which we welcome and even consider natural.

Aggression is an integral part of competitive sports and its appearance is inevitable in some sports. Martial arts can be considered such sports specifically, but also sports that require contact, such as water polo, which has become central to the present research. However, the aggression that emerges and its extent is influenced by a number of factors, such as referee judgments, the status of the match, or the players' positions and responsibilities. Based on these, a large degree of individual differences can be observed between athletes, which can result from personality differences, but even from meeting the requirements of the role in the sport. 


\section{AGGRESSION}

Aggression based on Baron's words is a form of behavior aimed at intentionally injuring or damaging another living being in a way that the victim wants to avoid (1977, quoted by NAGYKÁLDI, 1998). According to another definition, any intentional behavior that is intended to cause pain or harm to someone or something in an open or symbolic way is considered aggression (RANSCHBURG, 2012). A common feature of the two definitions is that it considers intentionality to be an essential criterion of aggression, but this is not easy to judge in most cases.

Comparing the various theories of aggression previously formulated by many researchers, it can be said that the reason for the appearance of aggression is to be found in innate urges, but this is supplemented by the changes in people by reinforcement as well as model learning (BIRD, 1986).

Researchers distinguish between different types of aggression, of which perhaps the bestknown grouping distinguishes between hostile and instrumental aggression. The primary goal of hostile aggression is to cause physical pain or psychological injury to achieve an end result. In contrast, in the case of instrumental aggression, the aggressive action can be traced back to other causes. In this case, the main motivation is to prevent another person from acting and as a result, to cause pain or injury (SILVA, 1980, quoted by DEHGHANI - BEHTAJ, 2012).

Haller (2005) grouped aggression according to its manifestations. Physical aggression is an instinct that is also present in the animal kingdom, making it the most universal form of aggression. However, because humans have the ability to speak, this provides another opportunity for the manifestation of aggression, which is called verbal aggression. The aim is to use violence in the same way, but in this case, it takes the form of a threat. This threat can take many forms, such as a change in tone, covert targeting, but the detection of open resentment is also included.

\section{AGGRESSION IN SPORT}

It is common at sporting events for competitors to turn to aggression to achieve victory or dominance. Outside of wartime, sport is perhaps the only environment in which aggressive actions are tolerated or even considered acceptable (GLYN et al., 1986; quoted by TOMAR - SINGH, 2012). Some believe that sport has historically evolved as a means of redirecting aggression to a culturally acceptable form (TOMAR - SINGH, 2012). The previously mentioned definition of aggression formulated by Baron (1977) was supplemented by Maxwell (2004, quoted by GADANECZ et al., 2016) to fit the world of sport. According to this, aggression in sport is a behavior that cannot be considered regular in a given sport and that happens against an opponent, teammate, fan or official who tries to avoid it. As mentioned earlier in relation to aggression, intentionality in sport is also a key factor that may appear in causing intentional injury (HUSMAN - SILVA, 1984, 
quoted by GRANGE - KERR, 2010). It is also important to mention that aggressive manifestations in sport usually take the form of unsportsmanlike conduct (EKLUND TENENBAUM, 2014).

A number of variables have been identified over the years that influence whether or not an athlete behaves aggressively during a match or stakes situation. One such factor is the degree of aggression previously committed against the player. The player against whom the opponent has acted aggressively during the match, himself will reciprocate in this way thus creating a kind of balance. It has been observed that the individual or team to lose commits more irregularities, which seems logical when considering that the feeling of loss is a major frustration for athletes. In relation to this, the outcome of the competition also has an effect on the appearance of aggression. If the result is very close, an irregularity can even determine the outcome of the game, so in these cases, less aggressive manifestations have been identified. In addition, neither a large score nor goal difference gives rise to the use of violence, so it has been found that most irregular behaviors are observed in the presence of a moderate amount of goal difference (VOLKAMER, 1971; quoted by BIRD, 1986). Furthermore, ranking in the league also influences aggressive behavior, with lower rankers being more aggressive (SOFIA - CRUZ, 2017). In addition, the violent reaction of fans also increases the amount of aggression of the players. Even the position of a player is a mediator factor due to the different tasks. Those who are more physically in contact with their opponents' have a bigger degree of aggression than isolated athletes, such as goalkeepers (VOLKAMER, 1971; quoted by BIRD, 1986).

Research has found that team sports show higher levels of aggression than individual sports (BARON - RICHARDSON, 1994; BEBETSOS - KONSTANTOULAS, 2006; quoted by BEBETSOS et al., 2013). In team contact sports, such as water polo, aggression is sanctioned, allowed under certain rules, which act as a kind of contract among athletes in the emergence of aggression (KERR, 1997; quoted by GRANGE - KERR, 2010). However, in terms of team sports, aggressive behavior can have mixed consequences (BROWN, 2000, quoted by DEHGHANI - BEHTAJ, 2012). An athlete's aggressive behavior can also negatively affect a team, as it can distract teammates that can also disrupt the game or force them to change tactics.

\section{SPORTSMANSHIP}

Sportsmanship's foundation is fair play, which means pure, honest and noble play. The definition of sportsmanlike behavior is very problematic, usually interpreted as observing the rules, but it is much more than that. It includes respect for the opponent, acting in the spirit of correctness, creating equal opportunities, and unconditional acceptance of refereeing decisions (PRZYLUSKA-FISZER, 1993, quoted by KO, 2016). Another wellknown concept of sportsmanship is also pure-play, according to which, victory is achieved only if it is achieved by pure tools, with equality in mind, excluding any fraud. Sportsmanship is essentially a moral way of life, a positive ideal that is the essence of sport (KO, 2016). 
Political, economical and social trends and external influences are already infiltrating the world of sport today, making it increasingly difficult for pure-play and sportsmanship to prevail (KO, 2016). However, under the Sports Act, non-compliance with the basic human ethical and moral requirements set out therein is sanctioned by the Penal Code (RESCH, 2019).

We can also talk about sportsmanship in relation to teams. In the case of team sports, there are critical situations in which a player's unsportsmanlike conduct can have negative consequences for the entire team. Therefore, in terms of teams, collective responsibility, the positive-negative effect on each other can be particularly decisive (KO, 2016).

\section{WATER POLO POSITIONS}

As with all team sports, in water polo players play in different positions. During the match, only seven players from one team can be in the pool at a time. Accordingly, we distinguish seven different positions. The goalkeeper is the keeper of the net who, using his good reflexes, tries to block the opponents' shots. The center back is the defensive player whose job it is to inactivate the goal-scoring center forward from shooting. In terms of the position of the center forward, it is the attacking player closest to the opponent's goal, whose job is to get out of the grip of the defensive center back and thus create a goal situation (MERÉSZ, 2011).

In water polo, we distinguish between two winger players, but unlike in other sports, we do not name them here based on the side they play at, but which hand the ball arrives at on the side where they are. Thus, if in an offensive situation a player with the right hand is on the left, the ball comes to him from his right side, accordingly this side is called the bite side and the position is called the left-winger. In contrast, the right-hand player receives the ball from the wrong hand's side, so this position is called right-winger. Players who are rearward from the wings are called drivers and, depending on which side they are on, they are called left or right drivers (BÍRÓ, 2011). There's a point position as well, who runs the offense. These positions are the ones that, by pulling the defense apart, try to score a goal into the opponent's goal. In this study, these positions were combined to be defined as "shooters" because of the similarity of their tasks.

Water polo is a sport that places high physical and physiological demands on the players, so athletes who play this sport tend to be tall and have a lot of muscle mass. However, there are differences in physical aptitude in terms of positions. Center forwards and center backs playing in the middle tend to be larger and have a higher percentage of body fat than players in other positions. This is an advantage for them as they have to keep the position near the goal while fighting the opponent's players. Those in perimeter positions, on the other hand, tend to be physically smaller, as speed, explosiveness, and agility are more important in these positions (COX et al., 2014). 


\section{RESEARCH QUESTIONS}

The focus of the present research is whether there is a difference between aggression in the different positions in water polo. In other words, whether a position determines the aggressive behavior of a particular player. This suggestion is supported by the roles that emerge during team development and that determine the behavior expected of the members. The aim was also to assess the effect of physical abilities on aggression. In addition, the research also focuses on sportsmanship, which, based on previous experience, is inversely related to aggression, however, a water polo sample has not yet been surveyed.

H1: There is a difference in the scores on the Buss-Perry Aggression Questionnaire due to the differences in the roles played in the game and their tasks.

H2: Regarding the subscales of the Buss-Perry Aggression Questionnaire, there is a difference between the positions.

H2a: In the case of water polo players in the goalkeeper position, verbal aggression and anger scores are higher than in the other three positions due to the lack of physical contact.

H3: Players with higher weight and height have a greater degree of aggression due to taking advantage of their physical strength.

H4: Aggression and sportsmanship show inverse proportionality to the whole sample, as a higher degree of aggression leads to more irregularities, and thus to less sportsmanlike behavior.

H5: Looking at the overall sample, water polo-specific aggression, number of personal fouls, and number of contra fouls correlate with scores on the Buss-Perry Aggression Questionnaire.

H6: Water polo players who belong to the highly aggressive group in terms of brutality are more aggressive than those who belong to the moderately aggressive or absolutely non-aggressive groups.

H7: Aggressive manifestations of players in water vary from position to position, as physical contact differs from position to position.

H8: In the case of older players, less aggression is observed both in terms of aggressive manifestations in the water and in terms of the score obtained in the Buss-Perry Aggression Questionnaire, as age and experience influence attitudes towards sports.

\section{METHODS}




\section{INTRODUCTION OF THE SAMPLE POPULATION}

The sample includes male water polo players ( $\mathrm{N}=96)$ who are more than 18 years of age and are actively participating in matches. The qualifiers could be divided into four groups based on their positions played in the matches. These positions are goalkeepers $(n=12)$, center forwards $(n=12)$, center backs $(n=26)$ and shooters $(n=46)$.

\section{TEST EQUIPMENT}

\section{AGGRESSIVE MANIFESTATIONS IN THE WATER}

Athletes had to state their actions on a five-point Likert scale and decide how likely they are to perform actions during matches that were aimed at holding back an opponent and thus qualifying as aggressive behavior. We called these water polo-specific aggression, which were: punching, kicking, scratching, grabbing swimming trunks, verbally insulting and pulling the string of a cap. In addition, they were tasked with responding to the number of irregularities committed during matches. These include personal fouls, contra fouls, brutality foul, and misconduct foul. The latter two are considered serious irregularities in water polo that in themselves show a high degree of aggression, thus not occurring with the same frequency as personal fouls or contra fouls. Thus, in these cases, the players only had to answer the question of whether there had been an example in their career when they had received such a penalty. A personal foul can be given to a player a maximum of three times during a match, after which the player cannot return to the game, so in the case of personal fouls, athletes could give their answers in the range of zero to three. The number of contra fouls are not maximized per match, so players are free to enter a value for this variable.

\section{SPORTSMANSHIP ATTITUDE SCALE}

To measure sportsmanship in our study, the Sportsmanship Attitude Scale was used (OMRAN, 2010). The measuring device is designed to measure the sportsmanlike manifestations of team athletes. There are 50 items in the questionnaire, in which case the person filling out the questionnaire should indicate on a five-point Likert scale how accurately read the statements describe them. The questionnaire can be divided into eight factors, which are: sportsmanship attitude toward opponents, sportsmanship attitude toward the referee, sportsmanship attitude toward fans, sportsmanship attitude toward team-mates, sportsmanship attitude toward the sports officials, sportsmanship attitude toward the media, sportsmanship attitude toward sports administrative staff, sportsmanship attitude toward colleagues. The score achieved in the questionnaire provides information on the degree of sportsmanship. 
In the study, respondents completed the Buss-Perry Aggression Questionnaire (1992) to measure aggression. The questionnaire includes 29 items for which the respondent should rate on a five-point Likert scale the extent to which a particular statement is characteristic of him. In addition to aggression as a personality trait, we also get information about the person filling out four subscales, which are physical aggression, verbal aggression, anger, and hostility. The higher a person's scale value is, the greater the degree of aggression.

\section{RESULTS}

The analysis of the results was started in each case by examining the normality of the results of the groups in question, during which, with one exception, a significance level of 0.05 was applied, and then the necessary parametric and non-parametric procedures were performed accordingly.

We hypothesized that in terms of the overall score achieved on the Buss-Perry Aggression Questionnaire, differences would be observed at different player positions. To prove this, a normality test was first performed for each group, followed by a Kruskal-Wallis test. Based on this, there is a significant difference in the overall aggression between the positions $(\chi 2(3)=8.889 ; p=0.031)$. In order to find out which groups differ there, a MannWhitney $\mathrm{U}$ test was performed. In doing so, there was no significant difference between the groups in terms of overall aggression $(p \leq 0,018)$. It should be noted, however, that a reduced level of significance was used to test this hypothesis $(\mathrm{p}=0.0083)$.

We also hypothesized that there would be differences in the positions regarding the subscales of the Buss-Perry Aggression Questionnaire (verbal aggression, physical aggression, anger, and hostility). We first performed a normality test, and since none of the groups followed a normal distribution based on the test, the analysis was continued by performing a Kruskal-Wallis test. This revealed that differences in positions were observed only in terms of verbal aggression $\left(\chi^{2}(3)=13,603 ; p=0,003\right)$. With center forwards proving to be more verbally aggressive than shooters $(W=1210,5 ; p=0,005)$ and goalkeepers ( $W=104 ; p=0,008)$.

Based on the statistical analysis performed in this hypothesis, the second hypothesis was not confirmed by our sub-hypothesis, which predicted significantly higher verbal aggression and anger in the goalkeeper position.

Considering the physical attributes of water polo players, we expected a correlation between physique and aggression. Physique was assessed through two indicators, which were body weight and body height. To test this, we first performed a normality test, followed by Spearman's rank correlation. Based on this, there is a significant, positive and moderate relationship between body weight and overall aggression, as well as body height and overall aggression. The correlation coefficients can be seen in Table 1. 


\begin{tabular}{|l|c|c|}
\hline & Weight & Height \\
\hline Overall aggression &, $345^{*}$ &, $326^{*}$ \\
\hline$p<0,05$
\end{tabular}

We also hypothesized that an inverse relationship would be observed between the overall scores of aggression and sportsmanship. Following the normality test, the data were analyzed using Pearson's correlation. The result shows that there is no relationship between the two variables, so aggression and sportsmanship show inverse proportionality $(\mathrm{p}=0,392, \mathrm{r}=0,088)$ (Figure 1).

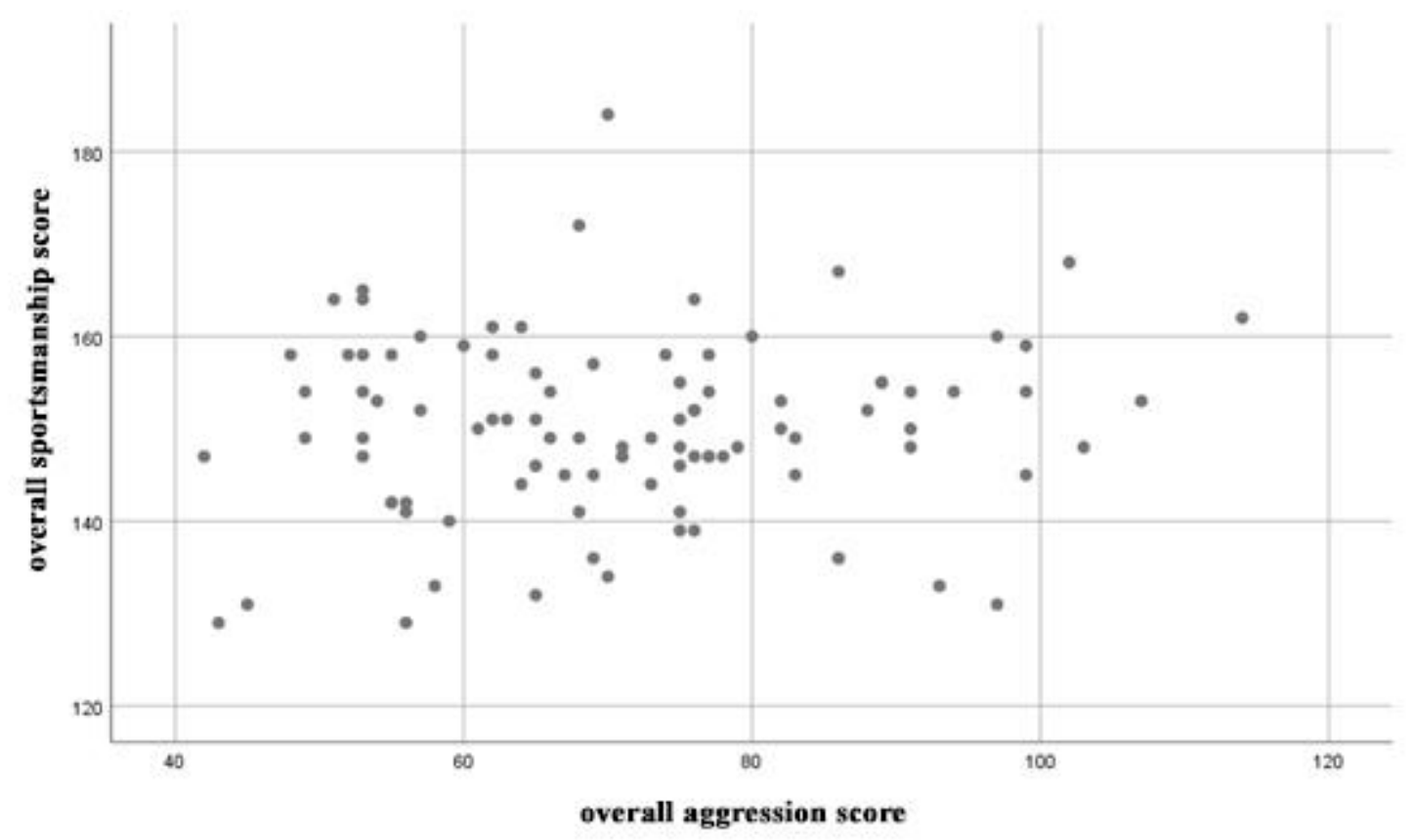

Figure 1: Demonstration of the relationship between aggression and sportsmanship

We previously thought that a correlation could be found between the total score on the Buss-Perry Aggression Questionnaire and the aggressive manifestations in the water. Due to the differences in the degree of aggression, it was not possible to summarize in one measure the different manifestations of aggressive manifestations in the water, so they were compared separately with the total score obtained in the questionnaire. Regarding water polo-specific aggression, the data do not follow a normal distribution, so I compared it with Spearman's rank correlation with the overall aggression score of the questionnaire. Based on this, there is a significant, positive, and moderately strong relationship between the two variables $(p<0,001, \rho=0,420)$ (Figure 2). In the case of the number of personal fouls, there was also a significant, positive, medium-strength relationship based on Spearman's rank correlation with the total score achieved on the Buss-Perry Aggression Questionnaire $(p<0,001, \rho=0,471)$. Examined by the Spearman's rank correlation with the contra fouls obtained during the matches, there is no relationship between them and overall aggression $(p=0,153 ; \rho=0,147)$. 
Based on all this, it can be said that the water polo-specific aggression and the connection of these variables with the questionnaire were confirmed in the case of the personal fouls, but in the case of the contra fouls, the hypothesis cannot be supported.

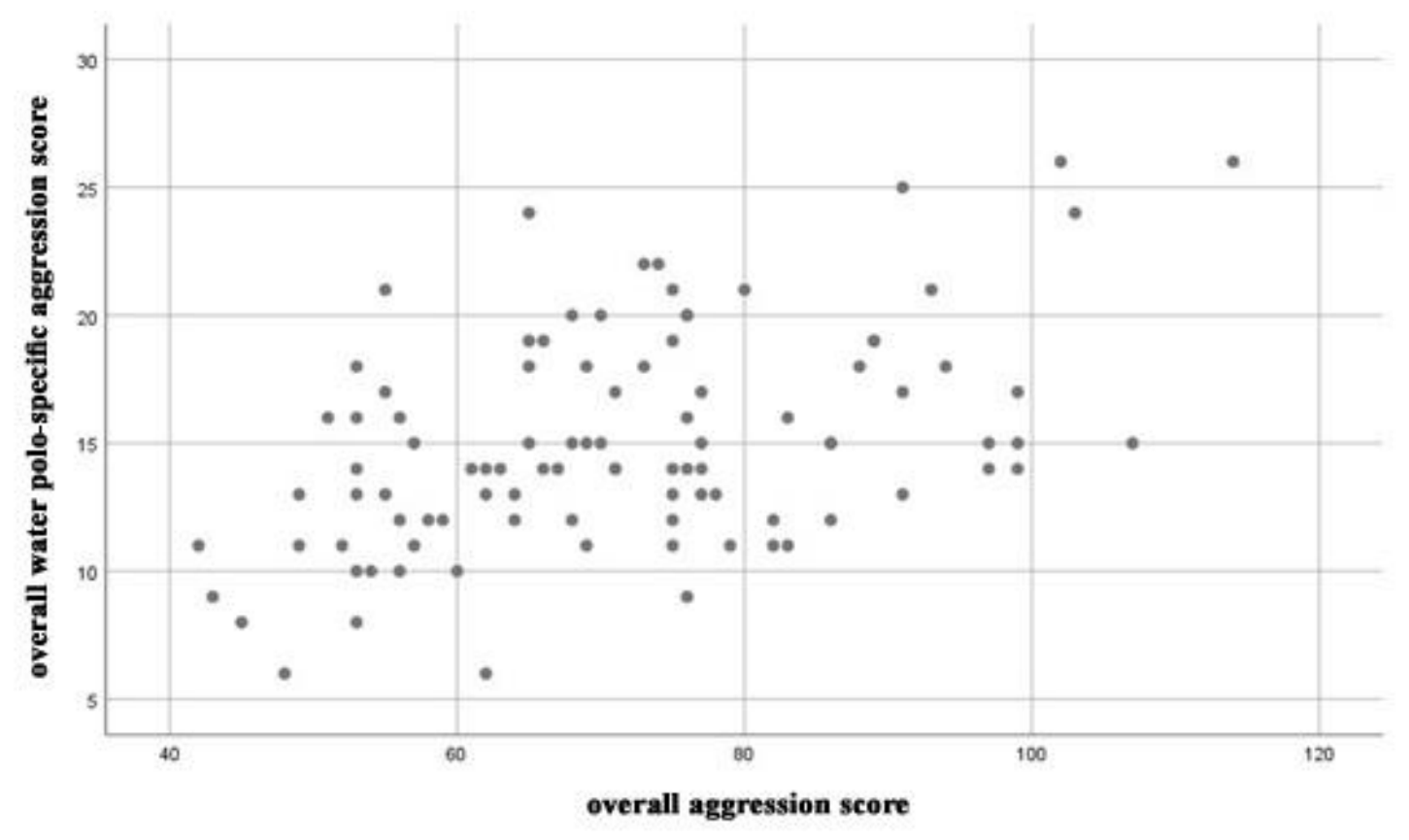

Figure 2: Comparison of the total score of the aggression achieved in water polo-specific aggression and the Buss-Perry Aggression Questionnaire

Our next assumption was that there were differences between the positions in terms of aggression as to whether the players had already been penalized for a brutality foul and/or misconduct foul during their careers. First, these groups were compared with water polo-specific aggression. To examine this, a one-way independent sample analysis of variance was used. Regarding water polo-specific aggression, the assumed standard deviations based on the Levene's test do not show accordance $(F(2 ; 93)=4.001 ; p=0.022)$. Thus, I used Welch's ANOVA, the results of which show that there is a significant difference between the values of the groups $(F(2 ; 56,180)=9.860 ; p>0.001)$. We used the Tamhan's T2 test for follow-up, it was found that athletes who belong to the highly aggressive group (who have already received both penalties) are more aggressive $(p<0,001)$ than water polo players in the moderately aggressive group (they received only one penalty) $(p=0,028)$. However, there is no significant difference between athletes who belong to the absolutely non-aggressive group (have not received any penalty) and those who can be said to be moderately aggressive $(p=0,055)$.

For comparison with the Buss-Perry Aggression Questionnaire, a one-way independent sample analysis of variance was used to test the hypothesis $(F(2 ; 93)=15,592 ; \mathrm{p}<0,001)$. Based on the Bonferroni correction it was found that athletes who belong to the highly aggressive group are more aggressive than water polo players who are absolutely nonaggressive in terms of brutality $(\mathrm{p}<0,001)$, or moderately aggressive water polo players $(p=0,011)$. However, there is no difference between those in the moderately aggressive 
and those in the absolutely non-aggressive groups $(\mathrm{p}=0,102)$. Thus, this assumption was confirmed.

In terms of aggressive manifestations in the water, we expected differences between player positions. In the case of water polo-specific aggression, the values of all four groups followed a normal distribution, so a one-way independent sample analysis of variance was used to test this hypothesis. Based on the Levene's test, the assumed standard deviations did not match $(F(3 ; 92)=2.880 ; p=0.04)$, so we performed a Welch's ANOVA, which resulted in a significant difference between the values of the groups $(\mathrm{F}(3 ; 28.024)=4.7 ; \mathrm{p}=0.009)$. Tamhane's $\mathrm{T} 2$ test was used for follow-up. It can be stated that there is a difference between the center forwards and the goalkeepers $(p=0,029)$, and there is also a significant difference between the center backs and the goalkeepers $(p=0,029)$. In all other cases, there was no significant difference in water polo-specific aggression ( $\mathrm{p} \geq 0,218$ ) (Figure 3).

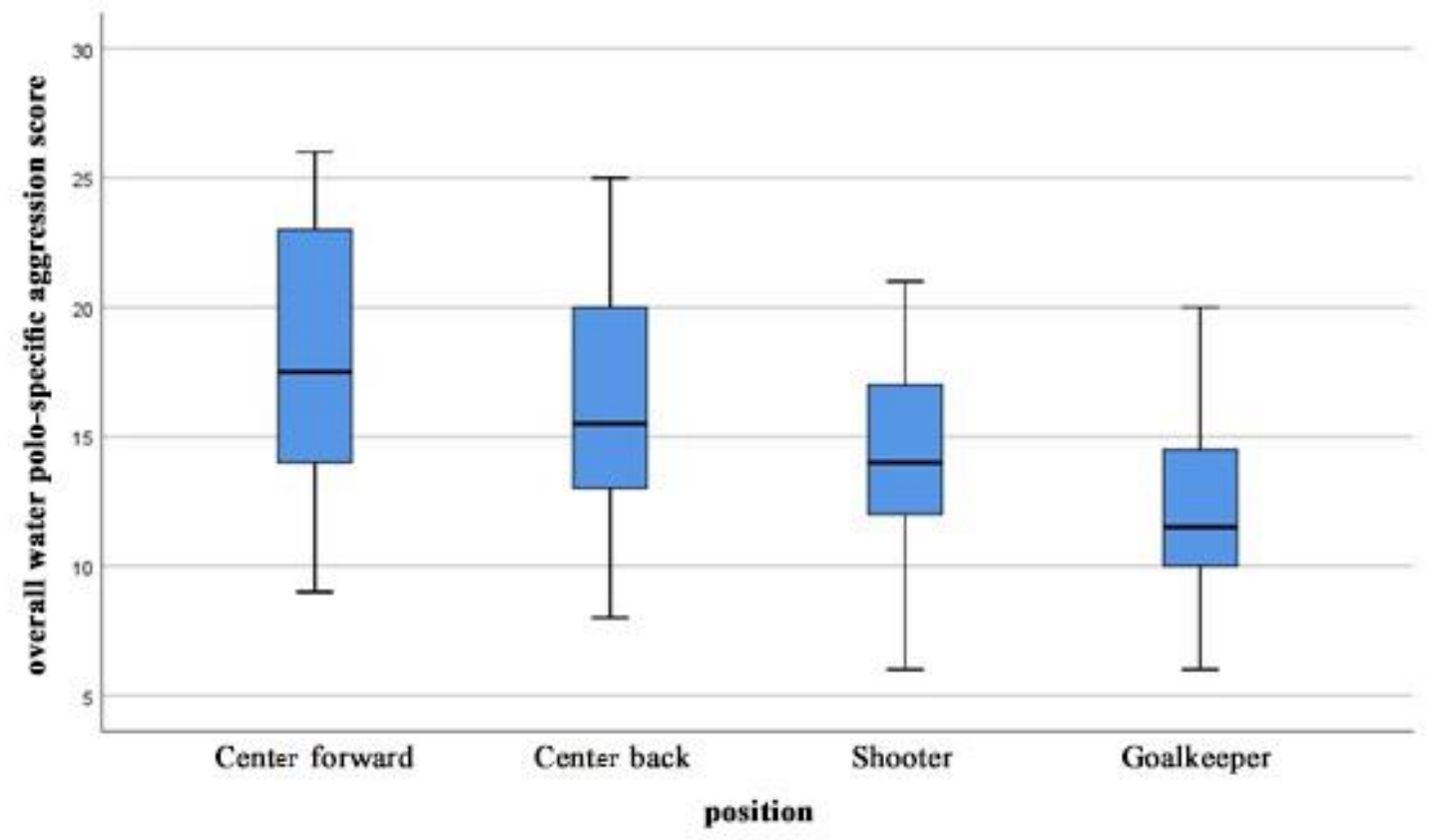

Figure 3: Appearance of water polo-specific aggression on different positions

To examine the relationship between personal fouls and positions, we used the Chisquared test. Based on the results of the Chi-squared test, the relationship between the two variables is significant. According to this, center backs are excluded at a higher rate than goalkeepers and shooters $\left(\chi^{2}(9)=69,367 ; p<0,001 ; \Phi=0,850\right)$. Frequences can be seen in table 2. 
Vol 4, No 2 (2021): Stadium -Hungarian Journal of Sport Sciences

Table 2: Frequency distribution of personal fouls appearing at positions

\begin{tabular}{|c|c|c|c|c|c|c|}
\hline & \multicolumn{4}{|c|}{ Number of personal fouls } & \multirow[b]{2}{*}{ Overall } \\
\hline & & $\mathbf{0}$ & 1 & 2 & 3 & \\
\hline \multirow{5}{*}{ Position } & Center back & 0 & 6 & 18 & 2 & 26 \\
\hline & Center forward & 0 & 4 & 5 & 3 & 12 \\
\hline & Goalkeeper & 10 & 2 & 0 & 0 & 12 \\
\hline & Shooter & 10 & 28 & 8 & 0 & 46 \\
\hline & Overall & 20 & 40 & 31 & 5 & 96 \\
\hline
\end{tabular}

When comparing the positions, the goalkeeper position was not analyzed for the contra fouls. This is because all goalkeepers in the sample gave zero contra fouls in response, so this group would have greatly skewed the results. The frequency distribution of contra fouls for center forward, center back, and shooter positions is summarized in table 3. In this case, too, a Chi-squared test was used to test the hypothesis. Based on the result of the Chi-squared test, there is a significant difference in the appearance of contra fouls in the positions $\left(\chi^{2}(10)=26,197 ; p=0,003 ; \Phi=0,558\right)$. According to this, the center forwards receive a higher proportion of contra fouls than center backs or shooters.

Table 3: Frequency distribution of contra fouls appearing at positions

\begin{tabular}{|c|c|c|c|c|c|c|c|c|}
\hline & \multicolumn{6}{|c|}{ Number of contra fouls } & \multirow[b]{2}{*}{ Overall } \\
\hline & & $\mathbf{0}$ & 1 & 2 & 3 & 4 & 5 & \\
\hline \multirow{4}{*}{ Position } & Center back & 7 & 8 & 4 & 3 & 3 & 1 & 26 \\
\hline & Center forward & 0 & 0 & 3 & 5 & 2 & 2 & 12 \\
\hline & Shooter & 7 & 21 & 11 & 6 & 0 & 1 & 46 \\
\hline & Overall & 14 & 29 & 18 & 14 & 5 & 4 & 84 \\
\hline
\end{tabular}

A Chi-squared test was also used to examine brutality at the position, based on which there is a significant difference between the positions in this respect (Table 4). Goalkeepers use a lower rate of brutality during matches, while center backs and center forwards use a higher rate of this form of expression $\left(\chi^{2}(6)=18,744, p=0,005, \Phi=0,442\right)$. 
Table 4: Frequency distribution of brutality at positions

\begin{tabular}{|c|c|c|c|c|c|}
\hline \multicolumn{2}{|c|}{} & \multicolumn{3}{|c|}{ Brutality } & \\
\cline { 3 - 6 } & $\begin{array}{c}\text { Absolutely } \\
\text { non- } \\
\text { aggressive }\end{array}$ & $\begin{array}{c}\text { Moderately } \\
\text { aggressive }\end{array}$ & $\begin{array}{c}\text { Highly } \\
\text { aggressive }\end{array}$ & Overall \\
\hline \multirow{4}{*}{ Position } & Center back & 3 & 13 & 10 & 26 \\
\cline { 2 - 6 } & Center forward & 0 & 5 & 7 & 12 \\
\cline { 2 - 6 } & Goalkeeper & 6 & 5 & 1 & 12 \\
\cline { 2 - 6 } & Shooter & 20 & 16 & 10 & 46 \\
\hline & Overall & 29 & 39 & 28 & 96 \\
\hline
\end{tabular}

Our last assumption was that age has an effect on players' aggression. The normality test revealed that the data did not follow a normal distribution, so Spearman's correlation test was used. Based on this, there is no significant difference in aggression by age, either in terms of the Buss-Perry Aggression Questionnaire $(p=0,538, \rho=0,064)$ or in terms of aggressive manifestations in the water $(p=0,453, \rho=0,078)$.

\section{DISCUSSION}

In our study, the aggressiveness of male water polo players was compared according to the positions held in the sport. This was based on the question of whether the athlete's position determines the level of aggression shown in the water or whether the player's personality influences the extent of his violence. In addition, the relationship between aggression and sportsmanship, previously examined by many researchers, has also been surveyed among male water polo players. In addition to the Buss-Perry Aggression Questionnaire, a series of self-formulated questions measuring water polo sport-specific aggression also helped to assess the difference in athletes' aggression. With this, the athletes' trait aggression became comparable as well as their aggression during matches. The Sportsmanship Attitude Scale was used to assess the sportsmanship of water polo players.

Based on the results of the research, it can be said that the aggression of the players in water polo is determined by the interaction of two factors. These are trait aggression 
based on the athletes' personalities, as well as the role they take on because of their position in the game in order to win.

It should also be noted that the sample confirmed the inverse relationship between aggression and sportsmanship already demonstrated by other researchers. Thus, this phenomenon also gained certainty in a water polo sample, according to which the more aggressive an athlete is, the less likely he is of sportsmanship.

Contrary to previous research by Zillmann (1979, quoted by BIRD, 1986), physically larger water polo players proved to be more aggressive than smaller physique players in terms of the present sample. Zillmann got the opposite result from observing football players, which he explained by the fact that for larger athletes, violence from their opponents causes less excitement, making them less likely to reciprocate with aggressive action. The result from the data of the present water polo sample may have been due to the one described by Cox, Mujika and van der Hoogenband (2014) that athletes with different physiques usually play different positions in water polo. This is due to the specifics and tasks of the positions. However, in the present sample, age is not one of the characteristics that influence the aggression of a water polo player.

After all, the research could be further expanded by studying other variables in order to gain more insight and a better understanding of the characteristics of aggression as well as sportsmanship in the sport of water polo.

\section{REFERENCES}

Bebetsos, E., Zouboulias, S., Antoniou, P., Kourtesis T. (2013). Do anxiety, anger and aggression differentiate elite water-polo players?. Journal of Physical Education and Sport, 13, (2), 209-212.

Bird, A. M. (1986). Psychology and sport behavior. Times Mirror/Mosby College Publishing.

Bíró M. (2011). Uszodai sportok. Budapest: Dialóg Campus Kiadó-Nordex Kft.

Cox, G. R., Mujika, I., van der Hoogenband, C. (2014). Nutritional Recommendations for Water Polo. International Journal of Sport Nutrition and Exercise Metabolism, 24, 382-391. https://doi.org/10.1123/ijsnem.2014-0003

Dehghani, M., Behtaj, A. (2012). The comparison of aggression of football players in different positions. Ovidius University Annals, Physical Education and Sport/Science, Movement and Health Series, 12, (2), 314-319.

Eklund, R. C., Tenenbaum, G. (2014). Aggression. In. R. Eklund, G. Tenenbaum (szerk.): Encyclopedia of Sport and Exercise Psychology (pp. 24-26). London: SAGE Publication. 
Gadanecz P., Kun Á., Takács V., Török L. (2016). Az agresszió, a düh és a szubjektív jóllét alakulása labdarúgócsapatoknál különböző téthelyzetekben. Alkalmazott Pszichológia 16, (3), 35-55.

Grange, P., Kerr, J. H. (2010). Physical aggression in Australian football: A qualitative study of elite athletes. Psychology of Sport and Exercise, 11, 36-43.

Haller J. (2005). Miért agresszív az ember? Budapest: Osiris.

Ko, A. (2016). Fair play. Budapest: Amfipressz.

Merész A. (2011). Labda a vízben. Budapest: MM Póló Bt.

Nagykáldi Cs. (1998). A sport és a testnevelés pszichológiai alapjai. Budapest: Computer Arts.

Omran, S. (2010). Construction of Sportsmanship Attitude Scale for Team Sports. World Journal of Sport Sciences, 3, 1111-1116.

Ranschburg J. (2012). Félelem, harag, agresszió. Budapest: Saxum.

Resch M. (2019). Sportpszichiátria: a sportolók lelki védelméért. Budapest: Krea-Fitt Kft.

Sofia R., Cruz J. F. A. (2017). Inveiling anger and aggression in sports: The effect of type of sport, competitive category and success level. Journal of Sport Psychology 26, (2), 21-28.

Tomar, R., Singh, R. (2012). Aggression in athletics: A comparative study. Ovidius University Annals, Physical Education and Sport/Science, Movement and Health Series, 12, (1), 31-34. 